\title{
Clinical Outcome and Predictive Factors of Variceal Bleeding in Patients with Hepatocellular Carcinoma in Thailand
}

\author{
Jitrapa Kerdsuknirun'1, Virunpat Vilaichone ${ }^{2}$, Ratha-Korn Vilaichone ${ }^{1,3,4 *}$
}

\begin{abstract}
Objective: Hepatocellular carcinoma (HCC) is common cancer in ASEAN. Variceal bleeding (VB) is considered to be fatal complication of cirrhosis with HCC. However, limited studies were reported in ASEAN. Aim of this study was to evaluate overall survival rate and predictors of VB in HCC patients. Methods: We conducted a retrospective cohort study of HCC patients aged $\geq 15$ years between January 2012-January 2016 and follow up through June 2016 at Thammasat University Hospital, Thailand. Clinical information and radiologic findings were collected from reviewing computer database of medical records. Results: 333 patients had completely retrievable information. Of which, 27 patients $(8.1 \%)$ had documented with VB. Clinical presentations with weight loss and jaundice were higher in VB than non-VB groups $(40.74 \%$ vs. $34.64 \%, p=0.525$ and $7.41 \%$ vs. $2.29 \%, p=0.116)$ but the differences were not significant. The most common causes of cirrhosis in HCC patients with VB were chronic HBV infection (55.56\%). In multivariate analysis; presence of ascites, Child-Pugh score $>6$, presence of varices were independent risk factors of having VB in $\mathrm{HCC}$ patients $(\mathrm{OR}=7.59,95 \% \mathrm{CI}=1.13-50.88, \mathrm{p}=0.037 ; \mathrm{OR}=5.07,95 \% \mathrm{CI}=1.08-23.76, \mathrm{p}=0.039 ; \mathrm{OR}=23.51$, $95 \% \mathrm{CI}=4.71-117.35, \mathrm{p}<0.001$, respectively). In HCC patients with VB, 1-year and 2.5-year survival rates were $56.6 \%$ and $28.3 \%$. Conclusions: HCC patients with ascites, Child-Pugh score $>6$ and presence of varices might be important predictive factors of VB. Having VB were greatly impact to the survival rate of HCC patients. Clinical suspicion and regular surveillance of VB in HCC patients at risk could improve treatment outcomes.
\end{abstract}

Keywords: Hepatocellular carcinoma- variceal bleeding- Thailand

Asian Pac J Cancer Prev, 19 (11), 3301-3305

\section{Introduction}

Hepatocellular carcinoma (HCC) is the sixth most common cancer and leads to major cancer related death worldwide (El-Serag, 2011; Kaneko et al., 2017; Chuncharunee and Siramolpiwat, 2017; Loho et al., 2016; Intaraprasong et al., 2016 ). In Thailand, HCC is the most common cancer in men and the third most common cancer in women (Somboon et al., 2014). The patients with HCC mostly have underlying chronic liver disease including liver cirrhosis (Bosch et al., 2005). The incidence of HCC is increasing in several developing countries, including Thailand and its dominant causes were related to hepatitis $\mathrm{B}$ virus, hepatitis $\mathrm{C}$ virus and alcoholic cirrhosis (Liang et al., 2013; Chunlertrith et al., 2000; Loho et al, 2016; Wiangnon et al., 2012; Wanich et al., 2016).

Variceal bleeding is one of the most serious complications of advanced cirrhosis and portal hypertension, which is considered a medical emergency and associated with significant mortality of $10-20 \%$ at 6 weeks (Graham and Smith, 1981; De Franchis, 2015). The incidence of HCC patients presenting with variceal bleeding ranging from $1 \%-15 \%$ (Lang et al., 2004). HCC is one of several factors that have been associated with increased mortality for an episode of variceal bleeding (D'Amico and De Franchis, 2003). The overall survival of HCC patients presenting with variceal bleeding was significantly worse than symptomatic HCC patients without VB with the median survival of 3.5 months vs. 5 months (Lang et al., 2004). The recommended management of variceal bleeding is combination of vasoactive agents and endoscopic variceal ligation (EVL) or endoscopic therapy with tissue adhesive agents depending on types of varices and considering early transjugular intrahepatic portosystemic shunt (TIPS) placement in cases with high risk of treatment failure (De Franchis, 2015). Although successful EVL significantly reduced mortality in HCC patients with VB, the overall survival was still poor in this group of patients (Chen et al., 1995,)

However, there are few reports of predictors for variceal bleeding in patients with HCC and overall survival of these patients. Aim of this study was to evaluate

${ }^{1}$ Gastroenterology Unit, Department of Medicine, Faculty of Medicine, Thammasat University Hospital, ${ }^{2}$ Patumwan Demonstration School, Srinakharinwirot University, Bangkok, ${ }^{3}$ Gastric Cancer and Gastrointestinal Diseases Research Center, ${ }^{4}$ Department of Medicine, Chulabhorn International College of Medicine (CICM) at Thammasat University, Pathumthani, Thailand. *For Correspondence: Vilaichone@hotmail.co.th 
predictive factors and overall survival of HCC patients with variceal bleeding in Thailand.

\section{Materials and Methods}

From January 2012 to January 2016, 371 patients were diagnosed with HCC and visited Thammasat University Hospital. Among them, 333 patients (89\%) had completely retrievable information. All the clinical information, laboratory and radiologic findings of these 333 patients were retrospectively reviewed.

HCC was diagnosed by one typical radiologic imaging examination showing characteristic features of HCC, or two different radiologic imaging examinations to confirm characteristic features of HCC, or by histology confirmation of HCC. Variceal bleeding was defined as bleeding from an EV or GV confirmed by endoscopy or presence of a sign of recent bleed on a varix or presence of EVs with red signs and presence of blood in the stomach in the absence of another source of bleeding (Sarin et al., 2011).

The patients were divided into HCC patients with and without variceal bleeding. Data including demographics, clinical presentations, laboratory findings and overall survival were compared between 2 groups. The study was conducted according to the good clinical practice guideline and was approved by ethics committee of Thammasat University Hospital, Pathumthani, Thailand.

\section{Statistical analysis}

Continuous data were reported as mean and standard deviation, and compared by the Student $t$ test or by the Mann Whitney U test where appropriate. Discontinuous data were reported as percentage and compared by the Chi-squared test or Fisher's exact test where appropriate. Probability of survival curves were obtained by the Kaplan-Meier method and compared by the log-rank test. The survival period defined as the length of time from the onset of the diagnosis of HCC to the death of the patient or the closing date of the study. The closing date for the study was June 30, 2016. Multivariate analyses were performed using Cox regression model. Differences were considered significant at 0.05 . All analyses were performed by using SPSS Statistics version 23.0 (IBM Corp., Armonk, NY)

\section{Results}

\section{Clinical characteristics of the patients}

A total of 371 patients with HCC, there were 333 patients had completely retrievable information. Of the 333 patients, $79 \%$ were male and the mean age was $59.9 \pm 12.3$ years. Most of them $(99.1 \%)$ had cirrhosis. The most common causes of chronic liver disease were HBV infection (45.9\%), followed by alcohol (31.5\%) and HCV infection (23.1\%). 19.8\% of them still had active alcohol drinking at diagnosis. Of all patients, $45 \%$ presented with abdominal discomfort, $35.1 \%$ presented with weight loss and $31.5 \%$ were asymptomatic. There were $48.9 \%, 45 \%$ and $5.4 \%$ of patients who had Child-Pugh A, B and C at inclusion. The mean MELD and MELD-Na scores were $11 \pm 4.9$ and $13.5 \pm 5.7$, respectively. According to BCLC staging system, HCC was diagnosed most frequently at stage B $(41.7 \%)$ with the mean of maximum size of tumors of $7.1 \pm 5 \mathrm{~cm}$. (range from $1 \mathrm{~cm}$. to $22 \mathrm{~cm}$.) as shown in table 1. Presence of major vessel thrombosis and metastasis were evident in $22.5 \%$ and $9.6 \%$ of all patients at diagnosis.

Prevalence of variceal bleeding and comparison of patients with and without variceal bleeding

There were 27 patients out of 333 patients $(8.1 \%)$ who had variceal bleeding. Passing melena $(25.9 \%$ vs. $1 \%$, $\mathrm{p}<0.001)$, presence of ascites $(14.8 \%$ vs. $2.3 \%, \mathrm{p}=0.001)$ at presentation were more frequent in $\mathrm{HCC}$ with $\mathrm{VB}$ group. The mean age of HCC patients with and without VB were not different. Causes of chronic liver disease were not significantly different between two groups. The mean of tumor size of VB group was significantly smaller than non-VB group $(5.44 \pm 3.23 \mathrm{~cm}$ vs. $7.2 \pm 5.14$ $\mathrm{cm}, \mathrm{p}=0.015)$. According to BCLC staging, the VB group had more HCC stage C $(40.74 \%$ vs. $19.28 \%$, $\mathrm{p}=0.009)$ and less HCC stage A (7.41\% vs. $28.1 \%$, p=0.019) than non-VB group at inclusion. The HCC patients with VB were more likely to had major vessel thrombosis at presentation $(76.47 \%$ vs. $66.67 \%, p=0.001)$. Those with VB had more Child-Pugh class B $(70.37 \%$ vs. $43.09 \%$, $\mathrm{p}=0.006)$ and class $\mathrm{C}(14.81 \%$ vs. $4.61 \%, \mathrm{p}=0.024)$ at inclusion than those without VB. The mean MELD scores were also higher in VB group $(15.48 \pm 11.88$ vs. $10.59 \pm 3.55, \mathrm{p}=0.043)$. Furthermore, the patients with VB had more refractory ascites $(7.41 \%$ vs. $1.31 \%, p=0.022)$, more presence of varices $(88.89 \%$ vs. $37.38 \%, \mathrm{p}<0.001)$ and sign of decompensation $(22.22 \%$ vs. $9.51 \%, p=0.039)$

Figure 1. Overall Survival of VB and non-VB Patients with $\mathrm{HCC}$

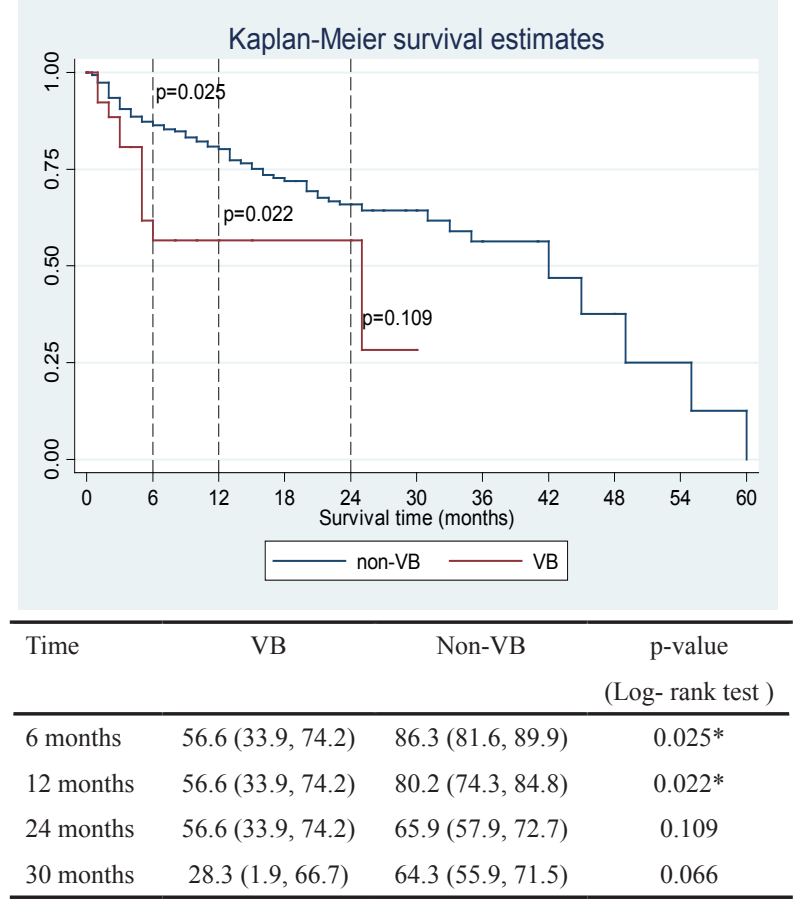

Values presented as survival probability and $95 \%$ Confident Interval (CI.). P-value corresponds to Log-rank test 
Table 1. Baseline Characteristics of All Patients

\begin{tabular}{|c|c|c|c|c|}
\hline & \multirow[t]{2}{*}{ Total $(n=333)$} & \multicolumn{3}{|c|}{ variceal bleeding vs. non-variceal bleeding } \\
\hline & & VB $(n=27)$ & non-VB $(n=306)$ & $\mathrm{p}$-value \\
\hline \multicolumn{5}{|l|}{ Sex } \\
\hline Male & $263(79 \%)$ & $25(92.59 \%)$ & $238(77.78 \%)$ & 0.07 \\
\hline Female & $70(21 \%)$ & $2(7.41 \%)$ & $68(22.22 \%)$ & 0.07 \\
\hline Age & $59.9 \pm 12.3$ & $59.48 \pm 11.64$ & $59.93 \pm 12.33$ & 0.855 \\
\hline \multicolumn{5}{|l|}{ Symptoms } \\
\hline asymptomatic & $105(31.5 \%)$ & $4(14.81 \%)$ & $101(33.01 \%)$ & 0.051 \\
\hline weight loss & $117(35.1 \%)$ & $11(40.74 \%)$ & $106(34.64 \%)$ & 0.525 \\
\hline jaundice & $9(2.7 \%)$ & $2(7.41 \%)$ & $7(2.29 \%)$ & 0.116 \\
\hline malaise/fatigue & $16(4.8 \%)$ & $0(0 \%)$ & $16(5.23 \%)$ & 0.223 \\
\hline anemic symptoms & $9(2.7 \%)$ & $0(0 \%)$ & $9(2.94 \%)$ & 0.366 \\
\hline \multicolumn{5}{|l|}{ Physical examination } \\
\hline ascites & $11(3.3 \%)$ & $4(14.81 \%)$ & $7(2.29 \%)$ & $0.001 *$ \\
\hline splenomegaly & $2(0.6 \%)$ & $0(0 \%)$ & $2(0.65 \%)$ & 0.674 \\
\hline \multicolumn{5}{|l|}{ Cause of CLD } \\
\hline alcohol & $105(31.5 \%)$ & $10(37.04 \%)$ & $95(31.05 \%)$ & 0.521 \\
\hline $\mathrm{HBV}$ & $153(45.9 \%)$ & $15(55.56 \%)$ & $138(45.1 \%)$ & 0.296 \\
\hline $\mathrm{HCV}$ & $77(23.1 \%)$ & $5(18.52 \%)$ & $72(23.53 \%)$ & 0.554 \\
\hline NASH & $13(3.9 \%)$ & $1(3.7 \%)$ & $12(3.92 \%)$ & 0.955 \\
\hline \multicolumn{5}{|l|}{ HCC BCLC stage } \\
\hline A & $88(26.4 \%)$ & $2(7.41 \%)$ & $86(28.1 \%)$ & $0.019 *$ \\
\hline $\mathrm{B}$ & $139(41.7 \%)$ & $9(33.33 \%)$ & $130(42.48 \%)$ & 0.355 \\
\hline $\mathrm{C}$ & $70(21 \%)$ & $11(40.74 \%)$ & $59(19.28 \%)$ & $0.009 *$ \\
\hline $\mathrm{D}$ & $36(10.8 \%)$ & $5(18.52 \%)$ & $31(10.13 \%)$ & 0.179 \\
\hline Mean of maximum size of mass & $7.1 \pm 5(1-22)$ & $5.44 \pm 3.23$ & $7.2 \pm 5.14$ & $0.015^{*}$ \\
\hline Major vessel thrombosis & $75(22.5 \%)$ & $13(76.47 \%)$ & $62(66.67 \%)$ & $0.001 *$ \\
\hline \multicolumn{5}{|l|}{ Child-Pugh score } \\
\hline A & $163(48.9 \%)$ & $4(14.81 \%)$ & $159(52.3 \%)$ & $<0.001^{*}$ \\
\hline B & $150(45 \%)$ & $19(70.37 \%)$ & $131(43.09 \%)$ & $0.006^{*}$ \\
\hline $\mathrm{C}$ & $18(5.4 \%)$ & $4(14.81 \%)$ & $14(4.61 \%)$ & $0.024 *$ \\
\hline MELD score & $11 \pm 4.9$ & $15.48 \pm 11.88$ & $10.59 \pm 3.55$ & $0.043^{*}$ \\
\hline MELD Na score & $13.5 \pm 5.7$ & $17.85 \pm 11.74$ & $13.07 \pm 4.65$ & $0.045^{*}$ \\
\hline Decompensation & $35(10.5 \%)$ & $6(22.22 \%)$ & $29(9.51 \%)$ & $0.039 *$ \\
\hline \multicolumn{5}{|l|}{ Signs of PHT } \\
\hline \multicolumn{5}{|l|}{ ascites } \\
\hline No & $216(64.9 \%)$ & $15(55.56 \%)$ & $201(65.9 \%)$ & 0.291 \\
\hline controlled & $110(33 \%)$ & $10(37.04 \%)$ & $100(32.79 \%)$ & 0.645 \\
\hline refractory & $6(1.8 \%)$ & $2(7.41 \%)$ & $4(1.31 \%)$ & $0.022 *$ \\
\hline varices & $138(41.4 \%)$ & $24(88.89 \%)$ & $114(37.38 \%)$ & $<0.001 *$ \\
\hline
\end{tabular}

Values presented as frequency (\%) and mean \pm SD; P-value corresponds to Independent's t test (Continuous data) and Chi square test or Fisher's exact test (Categorical data).

more than non-VB group as demonstrate in table 1. Serum total bilirubin, INR, albumin, Creatinine, AFP were also not different between two groups of patients.

Predictors for variceal bleeding in HCC patients and Overall survival of patients

By multivariate cox' regression analysis, presence of ascites, presence of varices and Child-Pugh scores $>6$ (child $\mathrm{B}$ or $\mathrm{C}$ ) at presentation were independently associated with variceal bleeding in HCC patients (Table 2).

Overall survival of HCC patients with variceal bleeding at 1 year and 2.5 years were $56.6 \%$ and $28.3 \%$, respectively and were decreased significantly compared with those without variceal bleeding at 1 year $(56.6 \%$ vs. $80.2 \%, \mathrm{p}=0.022$ ). 
Table 2. Predictive Factors of Variceal Bleeding (VB) in HCC Patients

\begin{tabular}{|c|c|c|c|c|}
\hline & \multicolumn{2}{|l|}{ Univariate analysis } & \multicolumn{2}{|c|}{ Multivariate analysis } \\
\hline & Crude OR & p-value & Adjusted OR $(95 \% \mathrm{CI})$ & $\mathrm{p}$-value \\
\hline Male & $3.57(0.85,31.79)$ & 0.07 & & \\
\hline age & $1(0.97,1.03)$ & 0.855 & & \\
\hline \multicolumn{5}{|c|}{ Physical examination } \\
\hline ascites & $7.43(1.47,31.42)$ & $0.001 *$ & $7.59(1.13,50.88)$ & $0.037 *$ \\
\hline hepatomegaly & $0(0, \mathrm{NA})$ & 0.766 & & \\
\hline splenomegaly & $0(0,22.39)$ & 0.674 & & \\
\hline Cirrhosis & $\mathrm{NA}(0.07, \mathrm{NA})$ & 0.605 & & \\
\hline \multicolumn{5}{|l|}{ Child-Pugh score } \\
\hline $\mathrm{A}$ & Reference & 1 & Reference & 1 \\
\hline $\mathrm{B}, \mathrm{C}$ & $6.38(2.1,25.88)$ & $<0.001^{*}$ & $5.07(1.08,23.76)$ & $0.039 *$ \\
\hline MELD score & $1.12(1.05,1.2)$ & $<0.001^{*}$ & $1.04(0.83,1.31)$ & 0.721 \\
\hline MELD Na score & $1.1(1.04,1.17)$ & $0.001 *$ & $0.98(0.82,1.18)$ & 0.828 \\
\hline Decompensation & $2.73(0.83,7.72)$ & $0.039 *$ & $0.19(0.03,1.18)$ & 0.075 \\
\hline \multicolumn{5}{|l|}{ Signs of PHT } \\
\hline ascites & $1.55(0.69,3.42)$ & 0.283 & & \\
\hline varices & $13.47(3.93,70.94)$ & $<0.001 *$ & $23.51(4.71,117.35)$ & $<0.001^{*}$ \\
\hline splenomegaly & $1.26(0.53,3.11)$ & 0.571 & & \\
\hline
\end{tabular}

Values presented as Odds ratio (OR) and 95\% Confident Interval (CI.); P-value corresponds to Logistic regression analysis

\section{Discussion}

Variceal bleeding is a vital complication of cirrhosis and associated with significant mortality of $10-20 \%$ at 6 weeks (Graham and Smith, 1981; De Franchis, 2015). The incidence of HCC patients presenting with variceal bleeding ranging from 1-15\% (Lang et al., 2004). HCC is shown to associated with increased mortality for an episode of variceal bleeding (D'Amico and De Franchis, 2003). The overall survival of HCC patients presenting with variceal bleeding was significantly worse than symptomatic HCC patients without variceal bleeding with median survival of 3.5 months vs. 5 months (Lang et al., 2004). Although successful endoscopic and pharmacologic treatment significantly reduced mortality in HCC patients with variceal bleeding, the prognosis of this group of patients was grave (Chen et al., 1995).

The severity of liver disease is a well-known risk factor of variceal bleeding in patients with cirrhosis and strongly affects prognosis (D'Amico and De Franchis, 2003; del Olmo et al., 2000). In our study, HCC patients with VB were more likely to have ascites and refractory ascites than those without VB, which reflect more advance degree of portal hypertension and decompensation. We also demonstrated that HCC patients with VB more likely to have Child-Pugh scores $>6$ (Child B and C) and higher MELD scores than those without VB, showing that more severe cirrhosis could contribute to variceal bleeding in HCC patients, which is consistent with prior studies (Lang et al., 2004). Result of portal hypertension directly caused by underlying severe cirrhosis rather than presence of HCC per se (Chen et al., 1998). We indicated that VB group had more HCC BCLC stage C and more major vessel thrombosis than non-VB group. HCC stage
$\mathrm{C}$, according to BCLC, is defined by patients either have major vessel thrombosis or metastasis or both. The major vessel thrombosis especially portal vein thrombosis which could occur in HCC or advanced cirrhosis (Kinjo et al., 2014) or tumor thrombus might also contribute to increases in portal venous pressure and finally led to variceal bleeding. The size of tumor were not different between 2 groups which consistent with previous report (Lang et al., 2004).

In our study, presence of ascites, Child-Pugh scores $>6$ (Child $B$ and $C$ ), presence of varices remained major predictive factors for VB in HCC patients. All reflected more severe cirrhosis and more degree of portal hypertension which undoubtedly explained VB coondition. We demonstrated the overall survival at 1 year and 2.5 years were $56.6 \%$ and $28.3 \%$, respectively and were decreased significantly compared with those without VB at 1 year (56.6\% vs. 80.2\%, $\mathrm{p}=0.022)$. MELD scores and presence of HCC were shown to be important prognostic factors in cirrhotic patients presenting with $\mathrm{VB}$ (D'Amico and De Franchis, 2003; Amitrano et al., 2005). Especially, MELD $>15$ is associated with high mortality risk in bleeding patients (Amitrano et al., 2005).

In summary, variceal bleeding is a fatal complication of cirrhosis and HCC leading to increased mortality rate. Our study indicated that presence of ascites, ChildPugh scores $>6$, presence of varices were independently associated with VB in HCC patients. The 1-year and 2.5-year cumulative survival of HCC patients with VB were $56.6 \%$ and $28.3 \%$, respectively and were decreased significantly compared with those without VB at 1 year (55.6\% vs. $80.2 \%)$. Having VB were greatly impact to the survival rate of $\mathrm{HCC}$ patients. Clinical suspicion and regular surveillance of VB in HCC patients at risk could 
be much improved in clinical outcomes.

\section{Acknowledgments}

This study was supported by research fund of the National Gastric Cancer and Gastrointestinal diseases Research Center, Pathumthani, Thailand.

\section{References}

Amitrano L, Guardascione MA, Bennato R, Manguso F, Balzano A (2005). MELD score and hepatocellular carcinoma identify patients at different risk of short-term mortality among cirrhotics bleeding from esophageal varices. $J$ Hepatol, 42, 820-5

Bosch FX, Ribes J, Cleries R, Diaz M (2005). Epidemiology of hepatocellular carcinoma. Clin Liver Dis, 9, 191-211.

Chen CH, Sheu JC, Huang GT, et al (1998). Characteristics of hepatocellular carcinoma presenting with variceal bleeding. J Gastroenterol Hepatol, 13, 170-4.

Chen CY, Chang TT, Lin CY, et al (1995). Endoscopic variceal ligation versus conservative treatment for patients with hepatocellular carcinoma and bleeding esophageal varices. Gastrointest Endosc, 42, 535-9.

Chuncharunee A, Siramolpiwat S (2017). Validation of the Hong Kong liver cancer staging system in patients with hepatocellular carcinoma after curative intent treatment. Asian Pac J Cancer Prev, 18, 1697-1701.

Chunlertrith K, Sukeepaisarnjaroen W, Mairiang P, et al (2000). Clinico-epidemiology of hepatitis $\mathrm{C}$ viral infection in northeastern Thailand. Southeast Asian J Trop Med Public Health, 31, 273-6

D’Amico G, De Franchis R (2003). Upper digestive bleeding in cirrhosis. Post-therapeutic outcome and prognostic indicators. J Hepatol, 38, 599-612.

De Franchis R (2015). Expanding consensus in portal hypertension: Report of the Baveno VI Consensus Workshop: Stratifying risk and individualizing care for portal hypertension. J Hepatol, 63, 743-52.

del Olmo JA, Pena A, Serra MA, et al (2000). Predictors of morbidity and mortality after the first episode of upper gastrointestinal bleeding in liver cirrhosis. J Hepatol, 32, 19-24.

El-Serag HB (2011). Hepatocellular carcinoma. $N$ Engl J Med, 365, 1118-27.

Graham DY, Smith JL (1981). The course of patients after variceal hemorrhage. Gastroenterology, 80, 800-9.

Intaraprasong P, Siramolpiwat S, Vilaichone RK (2016). Advances in management of hepatocellular carcinoma. Asian Pac J Cancer Prev, 17, 3697-703

Kaneko R, Nakazaki N, Omori R, et al (2017). The effect of new therapeutic and diagnostic agents on the prognosis of hepatocellular carcinoma in Japan - An analysis of data from the Kanagawa Cancer Registry. Asian Pac J Cancer Prev, 18, 2471-6.

Kinjo N, Kawanaka H, Akahoshi T, et al (2014). Portal vein thrombosis in liver cirrhosis. World J Hepatol, 6, 64-71.

Lang BH, Poon RT, Fan ST, Wong J (2004). Outcomes of patients with hepatocellular carcinoma presenting with variceal bleeding. Am J Gastroenterol, 99, 2158-65.

Liang T, Chen EQ, Tang H (2013). Hepatitis B virus gene mutations and hepatocarcinogenesis. Asian Pac J Cancer Prev, 14, 4509-13.

Loho IM, Hasan I, Lesmana CR, Dewiasty E, Gani RA (2016). Hepatocellular carcinoma in a Tertiary Referral Hospital in Indonesia: Lack of improvement of one-year survival rates between 1998-1999 and 2013-2014. Asian Pac J Cancer Prev, 17, 2165-70.

Sarin SK, Kumar A, Angus PW, et al (2011). Asian Pacific Association for the Study of the Liver (APASL) working party on portal hypertension. Diagnosis and management of acute variceal bleeding: Asian Pacific Association for Study of the Liver recommendations. Hepatol Int, 5, 607-24.

Somboon K, Siramolpiwat S, Vilaichone RK (2014). Epidemiology and survival of hepatocellular carcinoma in the central region of Thailand. Asian Pac J Cancer Prev, $15,3567-70$.

Wanich N, Vilaichone RK, Chotivitayatarakorn P, Siramolpiwat $S$ (2016). High prevalence of hepatocellular carcinoma in patients with chronic Hepatitis B infection in Thailand. Asian Pac J Cancer Prev, 17, 2857-60.

Wiangnon S, Kamsa-ard S, Suwanrungruang K, et al (2012). Trends in incidence of hepatocellular carcinoma, 1990-2009, Khon Kaen, Thailand. Asian Pac J Cancer Prev, 13, 1065-8.

This work is licensed under a Creative Commons AttributionNon Commercial 4.0 International License. 